\title{
A regional food-frequency questionnaire for the US Mississippi Delta
}

\author{
Katherine L Tucker ${ }^{1}$ * , Janice Maras ${ }^{1}$, Catherine Champagne ${ }^{2}$, Carol Connell ${ }^{3}$, \\ Susan Goolsby ${ }^{4}$, Judith Weber ${ }^{4}$, Sahar Zaghloul ${ }^{5} \uparrow$, Teresa Carithers ${ }^{6}$ \\ and Margaret L Bogle \\ 'Jean Mayer US Department of Agriculture (USDA) Human Nutrition Research Center on Aging at Tufts University, \\ 711 Washington Street, Boston, MA 02111 , USA: ${ }^{2}$ Pennington Biomedical Research Center, Baton Rouge, LA, \\ USA: ${ }^{3}$ University of Southern Mississippi, Hattiesburg, MS, USA: ${ }^{4}$ Arkansas Children's Hospital Research Institute, \\ Little Rock, AR, USA: ${ }^{5}$ University of Arkansas at Pine Bluff, Pine Bluff, AR, USA: ${ }^{6}$ The Jackson Heart Study, Jackson, \\ MS, USA: ${ }^{7}$ USDA Agricultural Research Service, Little Rock, AR, USA
}

Submitted 16 April 2004: Accepted 13 July 2004

\begin{abstract}
Objective: To describe food sources of nutrient intake for white and African American adults in the Lower Mississippi Delta (LMD), and their use in the development of a regional food-frequency questionnaire (FFQ) based on an earlier version of the National Cancer Institute's Health Habits and History Questionnaire.

Design: We ranked food sources of energy, macronutrients, vitamins and minerals, and examined portion size distributions for 842 white and 857 African American residents aged 19 years and older, using 24-hour dietary intake recall data from a telephone survey of 36 LMD counties. These values were used to develop a regional FFQ, which was then field-tested with 100 subjects and revised to improve interpretability.

Setting: The LMD region of the USA.

Subjects: White and African American adult residents of the LMD.

Results: LMD African Americans obtained more of their energy and nutrient intakes from poultry, processed meat, salty snacks, fruit drinks, pork and cornbread; and less from milk, alcohol, legumes, salad dressing, butter/margarine and sweetened tea than did white residents. Regional foods not on nationally used FFQs included grits, turnip greens, okra, ham hocks, chitterlings, crawfish, catfish, cracklings, jambalaya, potato logs, chicken and dumplings, and sweet potato pie. Based on responses during fieldtesting, the questionnaire was also designed to add four portion sizes for each food item, presented as questions, rather than in grid format.

Conclusions: Regional food use patterns differ from national patterns and furthermore differ between African American and white adults in the LMD. The resulting Delta NIRI FFQ for Adults should contribute to improved assessment of usual intake for use in studies of diet and health in this region.
\end{abstract}

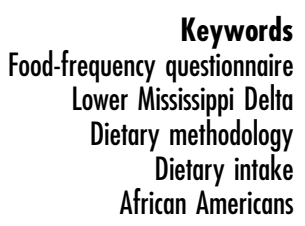

Despite limitations in the quantitative assessment of macronutrients ${ }^{1}$, the food-frequency questionnaire (FFQ) has proved to be a useful tool for ranking individuals' usual nutrient intakes for assessing associations between dietary components and health outcomes ${ }^{2}$. The most widely used FFQs have been designed to capture the foods most commonly consumed in the USA ${ }^{3,4}$. However, the intakes of individuals who follow very different dietary patterns from the national norm may be underestimated due to the absence of specific foods used from the food list, or may be incorrectly estimated due to differing

†Present address: University of Hawaii at Manoa, Honolulu, HI, USA. recipes for commonly used foods. When a different dietary pattern is prevalent in the population under study, the error may lead to extensive misclassification. In addition to attenuating the ability to relate dietary components to specific outcome measures, this may result in biased assessments of a group or subgroup. It is therefore important to test questionnaires and, if necessary, adapt them to each population under study.

The Lower Mississippi Delta (LMD) region of the USA is an important area in which to conduct nutrition research. One of the most impoverished rural regions in the country, it has higher than national average mortality rates from nutrition-related chronic diseases including heart disease and cancer ${ }^{5}$. Despite the key role that diet is known to play 
in the aetiology of these diseases, few studies have examined the potential role of diet in these excessive health risks. None of the major national nutrition surveys has collected dietary data in this region. One goal of the Lower Mississippi Delta Nutrition Intervention Research Initiative (Delta NIRI), funded by the US Department of Agriculture's (USDA) Agricultural Research Service, is to obtain data that will help clarify these associations and to identify effective nutrition interventions that may assist the population in reducing these risks. A telephone survey in the Delta region collected representative dietary data using 24-hour dietary recalls. A previous report of these data showed that intakes of most micronutrients were significantly lower in the LMD, relative to national data, and that this was particularly true among the African American subset ${ }^{6}$.

We used these data to develop a new FFQ (the Delta NIRI Food Frequency Questionnaire for Adults) designed for use in the LMD region. In this report, we present the methodology used for this development and highlight the uniqueness of foods, preparations and portion sizes used by African American and white adults in this region.

\section{Materials and methods}

Data on dietary intakes in this region were available from 24-hour dietary recalls collected in the Delta NIRI Foods of our Delta Survey 2000 (FOODS 2000), between January and June 2000. FOODS 2000 was a cross-sectional telephone survey of a representative sample of the population 3 years of age and older in 36 counties and parishes in the LMD of Arkansas, Louisiana and Mississippi. Each sample person provided a single 24-hour recall. A previous validation study conducted by Delta NIRI had confirmed the feasibility of using a telephone survey to collect dietary data within this region $^{7}$. For FFQ development, we selected data from adults aged 19 years and older $(n=842$ white and 857 African American) to describe the major food contributors to energy and nutrient intake, to identify commonly used portion sizes and to obtain recipes for unique food items. This information was then used to develop a regionally appropriate food list and portion size options for the FFQ; and to provide weighting and recipe information for the nutrient database used to analyse questionnaire responses.

\section{FOODS 2000 metbodology}

Westat (Rockville, MD, USA) conducted participant sampling, interviewer training and telephone interviews for FOODS 2000. Sampling was done using a two-stage stratified cluster design, as previously described ${ }^{6}$. Briefly, 36 Delta counties were assigned to nine strata according to population size, racial composition and income; and two sampling units (based on census definition) per strata were selected randomly. List-assisted methodology was used to select a sample of 4377 working residential telephone numbers in the 18 sample units. Response to the screener interview was $58.6 \%$, and a total of 2162 households agreed to participate. One adult per household was selected randomly to complete the 24-hour recall.

Thirty-three telephone interviewers completed a 4-day training session on administration of the dietary questionnaires, using food-measuring guides. The 24-hour dietary recall was conducted using the USDA multiplepass procedure ${ }^{8}$. Prior to completing the recall, the food measurement guide was mailed to participants for use during the interview. The response rate was $80.5 \%$. Data were coded, entered and analysed for nutrient content at the Pennington Biomedical Research Center using the USDA SurveyNet nutrient composition tables?

\section{Ranking of food contributions to nutrient intake}

The resulting food and nutrient variables from the survey were transferred to the Dietary Assessment and Epidemiology Research Program at the USDA Jean Mayer Human Nutrition Research Center on Aging at Tufts University. These were analysed for food contributions to energy and nutrient intakes, portion size distributions and recipe detail. Foods reported on the 24-hour dietary recalls were grouped into 140 food groups, based on similarity of nutrient composition and common usage. These food groupings are similar, though not identical, to the 112 groups used by Subar et al. in their description of the dietary sources of nutrients in the diets of US adults ${ }^{10}$. These food groups were then ranked by their percentage contribution to individual nutrients, using the RANK procedure in $\mathrm{SAS}^{11}$. Foods that contributed $0.5 \%$ or more to the intake of energy or any single nutrient were included in the list of foods on the questionnaire. Local names of foods were used, as appropriate, based on pretesting with adult groups in the LMD. Foods that did not appear on existing commonly used FFQs, but were relevant contributors to intake, were identified from these lists for inclusion on the new FFQ.

\section{FFQ form development, field trial and revision}

Beginning with an adapted version of the 1989 National Cancer Institute (NCI)-Block $\mathrm{FFQ}^{12}$, and following the methodology used in the development of that questionnaire, we revised the food list to include all foods that contributed at least $0.5 \%$ to any of the nutrients examined. Because of the extended distribution of portion sizes reported in the FOODS 2000 data, we replaced the small, medium and large designations with four target sizes, based on the distribution of portion sizes observed for each food.

Questions on the use of common vitamin and mineral supplement formulations, as well as separate use of 12 individual vitamin and mineral supplements, were also 
included so that total nutrient intakes could be calculated. Another modification, borrowed from the Harvard $\mathrm{FFQ}^{4}$, was the inclusion of open-ended responses for types of cereal most frequently consumed and for additional foods consumed at least once per week. These were coded directly onto the form prior to scanning, based on a code book of reported foods that can be adapted to include new responses linked to parallel additions to the database.

The draft form was field-tested at several community sites in the LMD and in Jackson, Mississippi. Using a variant of cognitive interviewing methodology, more than 100 questionnaires were interviewer-administered to individuals in the region. Reactions, difficulties or questions by respondents were noted systematically and discussed in depth at investigator meetings.

\section{Database development}

Nutrient data from the USDA SurveyNet database ${ }^{9}$ were used for the development of a nutrient database for the FFQ. Each food line represented several specific food items. Within each line item, the frequency of foods reported from the 24-hour dietary recall was ranked. For example, in the line 'Strawberries, other berries', all reported berries were ranked according to frequency of appearance in the dataset. Those contributing at least 5\% of reported usage were assigned a proportional share so that the sum of those included totalled 100\%. The nutrient value for each food was then weighted by this proportion to represent a composite food for the line.

In addition to weighting of specific foods, recipes for combination food items were added. For example, gumbo and jambalaya are local preparations that may vary from household to household. Specific recipe information collected during the FOODS 2000 24-hour dietary intake recall was examined to determine whether a standard recipe could be used. When multiple recipes were identified, they were ranked, as described above for foods, and the nutrient values of each were included in relative proportion to their reported frequency.

\section{Results}

\section{Food contributors to energy intake}

For this sample of both African American $(n=857)$ and white ( $n=842$ ) LMD adults, approximately $7 \%$ of energy came from soft drinks, followed by $6 \%$ from white bread, $4-5 \%$ from burgers or meatloaf and $3-4 \%$ from salty snacks. After that, however, food contributions differed considerably between the two racial groups. African Americans reported greater relative consumption than white LMD adults of fried chicken, sausage and fried fish; and lower relative consumption of salad dressing. Other top energy contributors for African Americans included cornbread and luncheon meat; while for white adults, these included beefsteaks and roasts, sweetened tea and milk (Table 1).

\section{Food contributors to macronutrient intake}

The top five food contributors of carbohydrate, protein, fat and dietary fibre are presented in Table 2 for LMD residents, by race. For both groups, the top sources of carbohydrate were soft drinks (15\%) and bread (about 9\%). Salty snacks were also important contributors to both groups. Cakes, muffins and sweetened tea contributed more carbohydrate intake for whites, and fruit drinks and candy for African Americans. The top protein source for African American adults was fried chicken, followed by burgers and meatloaf, poultry (not fried) and fried fish; while for white adults they included luncheon meats, and beefsteaks and roasts, but not fish. Fat sources also differed by race; white adults consumed more fat from salad dressings and cheese, and African Americans consumed more from fried chicken, sausage, salty snacks and fried fish. Both groups consumed the greatest proportion of fibre from white bread, followed by beans.

\section{Food contributors to vitamin intake}

Fortified white bread was the major source of folate for both groups (Table 3), followed by breakfast cereal, tea and orange juice. Breakfast cereals were also important contributors of vitamin $\mathrm{B}_{6}$ in this population along with bananas. African Americans consumed most of their vitamin $\mathrm{B}_{6}$ from fried chicken, while white adults consumed more vitamin $\mathrm{B}_{6}$ from beefsteaks and roasts. Although both groups consumed most of their vitamin $\mathrm{B}_{12}$ from burgers and meatloaf, white adults consumed relatively more from beefsteaks and roasts and milk, and less from fried fish, liver and sausage, than the African American adults.

While orange juice was the major source of vitamin C for both groups, African Americans consumed relatively more vitamin $\mathrm{C}$ from fruit drinks, while white adults consumed more from potatoes (Table 4). Vitamin A sources differed considerably by race. White adults consumed $10 \%$ of their vitamin A from carrots, but carrots were not within the top five sources for African Americans. Rather, the top source of vitamin A for African Americans was sweet potatoes, followed by chicken liver, greens and fried beef liver. The major source of vitamin E for African Americans was salty snacks (12\%), followed by fried fish, while for white adults the major source was mayonnaise and salad dressing.

\section{Food contributors to mineral intake}

White adults obtained 26\% of their calcium from milk, relative to less than 15\% for African Americans (Table 5). African Americans consumed almost 5\% of their calcium from cornbread. The largest source of iron for both racial groups was white bread, followed by breakfast cereal and beefsteaks and roasts for white adults; and ground beef, fried chicken and grits for African American adults. Beef was the major source of zinc for both groups. Other top sources included gumbo and luncheon meat for white adults, and poultry and sausage for African American 
Table 1 Top 20 contributors to energy intake in adults of the Lower Mississippi Delta, by race

\begin{tabular}{|c|c|c|c|c|}
\hline \multirow[b]{2}{*}{ Food } & \multicolumn{2}{|c|}{ White $(n=842)$} & \multicolumn{2}{|c|}{ African American $(n=857)$} \\
\hline & $\%$ & Rank & $\%$ & Rank \\
\hline Soft drinks & 7.0 & 1 & 7.1 & 1 \\
\hline White bread, rolls & 5.8 & 2 & 6.0 & 2 \\
\hline Burgers, meatloaf & 3.8 & 3 & 4.6 & 4 \\
\hline Salty snacks & 2.8 & 4 & 4.2 & 5 \\
\hline Cakes, muffins & 2.6 & 5 & 2.0 & 12 \\
\hline Mayonnaise, salad dressing & 2.4 & 6 & 1.4 & 20 \\
\hline French fries & 2.3 & 7 & 2.1 & 11 \\
\hline Fried chicken & 2.3 & 8 & 4.6 & 3 \\
\hline Beefsteaks, roasts & 2.2 & 9 & & \\
\hline Fried fish & 2.1 & 10 & 3.0 & 7 \\
\hline Cookies & 1.9 & 11 & 2.3 & 8 \\
\hline Tea, sweetened & 1.9 & 12 & & \\
\hline 2\% Milk & 1.8 & 13 & & \\
\hline Cheese & 1.7 & 14 & 1.5 & 19 \\
\hline Whole milk & 1.6 & 15 & & \\
\hline Other potatoes & 1.6 & 16 & & \\
\hline Biscuits & 1.6 & 17 & & \\
\hline Candy (not chocolate) & 1.5 & 18 & 1.9 & 13 \\
\hline Sausage & 1.4 & 19 & 3.1 & 6 \\
\hline Ice cream & 1.4 & 20 & 1.6 & 15 \\
\hline Cornbread & & & 2.1 & 10 \\
\hline Luncheon meat & & & 1.6 & 18 \\
\hline Spaghetti and sauce, lasagne & & & 1.6 & 16 \\
\hline Orange juice & & & 1.6 & 14 \\
\hline Fruit drinks & & & 2.2 & 9 \\
\hline Poultry, broiled & & & 1.6 & 17 \\
\hline $\begin{array}{l}\text { Intake, mean } \pm \text { standard deviation } \\
\text { Energy (kcal) }\end{array}$ & $\begin{array}{c}\text { Men } \\
2450 \pm 1107\end{array}$ & $\begin{array}{l}\text { Women } \\
1791 \pm 828\end{array}$ & $\begin{array}{c}\text { Men } \\
2327 \pm 1215\end{array}$ & $\begin{array}{c}\text { Women } \\
1672 \pm 925\end{array}$ \\
\hline
\end{tabular}

adults. Among white adults, the major magnesium sources were coffee and milk. In contrast, African Americans consumed the largest proportion (5\%) of their magnesium from salty snacks.

While these results describe differences in sources of these nutrients, and the comparison of nutrient intakes is the subject of another publication ${ }^{6}$, it is important to note that the African American men and women in this sample reported, on average, lower intakes of each of these minerals than did the white men and women. This was reflected in apparently unusual sources for some nutrients. For example, the average magnesium intakes were $248 \mathrm{mg}$ for African American men and $182 \mathrm{mg}$ for women (relative to current Recommended Dietary Allowances ${ }^{13}$ of 420 and $320 \mathrm{mg}$, respectively), and this is reflected in the fact that foods commonly consumed, like salty snacks, make larger contributions to intake than foods that are considerably better sources of the nutrient per serving.

\section{Foods added to the questionnaire}

Although only the top five food contributors of each nutrient are presented in the tables here for space considerations, regional foods identified from the 24-hour recalls that were seen to contribute more than $0.5 \%$ of any of the nutrients examined were included on the questionnaire (Table 6). These include grits, turnip greens, field peas, okra, ham hocks, chitterlings, squirrel, crawfish, catfish and cracklings. Regionally common preparations and recipes added to the database included broccoli and rice casserole, jambalaya, dirty rice, potato logs, chicken and dumplings, and sweet potato pie. In addition, local names for foods were added, such as 'chicken fried steak', a commonly used beef preparation. Because of the large contribution of drinks such as lemonade and powdered drink mixes for the African American group and sweetened iced tea for the white adults to the energy, carbohydrate and/or vitamin C intakes of this population, more specification of these categories was added to the FFQ. Incorporation of all foods reported on the 24-hour recalls that contributed at least $0.5 \%$ to the intake of energy or tested nutrients, separately for white and African American adults, captured more than $98 \%$ of reported energy and of each of the examined macronutrient, vitamin and mineral intakes for both race groups.

\section{Portion size}

The distributions of portion sizes of common foods on the FFQ were examined in the FOODS 2000 data. We present the 15 th, 50 th and 85 th percentiles in Table 7 . Examination of these distributions suggested that the inclusion of four portion size options on the questionnaire was necessary to capture the variation in reported portion sizes. For many foods, the 85th percentile exceeded two times the median. On most existing FFQs, a small portion is considered half of a medium portion, and a large portion is 1.5 times a medium portion. Using these designations would clearly underestimate some of the large portion sizes observed 
Table 2 Top food contributors to macronutrient intakes in adults of the Lower Mississippi Delta, by race

\begin{tabular}{|c|c|c|c|c|}
\hline \multirow[b]{2}{*}{ Food } & \multicolumn{2}{|c|}{ White $(n=842)$} & \multicolumn{2}{|c|}{ African American $(n=857)$} \\
\hline & $\%$ & Rank & $\%$ & Rank \\
\hline \multicolumn{5}{|l|}{ Carbohydrate } \\
\hline Soft drinks & 14.9 & 1 & 15.0 & 1 \\
\hline White bread, rolls & 8.5 & 2 & 8.7 & 2 \\
\hline Tea, sweetened & 4.1 & 3 & & \\
\hline Cakes, muffins & 3.5 & 4 & & \\
\hline Salty snacks (chips) & 2.7 & 5 & 3.9 & 4 \\
\hline Candy (not chocolate) & & & 3.3 & 5 \\
\hline Fruit drinks & & & 6.2 & 3 \\
\hline \multicolumn{5}{|l|}{ Protein } \\
\hline Burgers, meatloaf & 7.1 & 1 & 8.4 & 2 \\
\hline Beefsteaks, roast & 7.1 & 2 & & \\
\hline Fried chicken & 5.4 & 3 & 11.8 & 1 \\
\hline White bread, rolls & 4.5 & 4 & 4.7 & 5 \\
\hline Luncheon meat & 3.9 & 5 & & \\
\hline Fried fish & & & 5.0 & 4 \\
\hline Poultry, not fried & & & 5.6 & 3 \\
\hline \multicolumn{5}{|l|}{ Fat } \\
\hline Mayonnaise, salad dressing & 6.2 & 1 & & \\
\hline Burgers, meatloaf & 5.9 & 2 & 6.9 & 1 \\
\hline Salty snacks (chips) & 3.9 & 3 & 5.9 & 4 \\
\hline Fried fish & 3.3 & 4 & 4.8 & 5 \\
\hline Cheese & 3.3 & 5 & & \\
\hline Fried chicken & & & 6.4 & 3 \\
\hline Sausage & & & 6.4 & 2 \\
\hline \multicolumn{5}{|l|}{ Fibre } \\
\hline White bread, rolls & 7.9 & 1 & 9.1 & 1 \\
\hline Beans & 6.6 & 2 & 7.7 & 2 \\
\hline High-fibre cereal & 5.1 & 3 & & \\
\hline Salty snacks (chips) & 4.8 & 4 & 7.3 & 3 \\
\hline French fries & 3.8 & 5 & 3.6 & 4 \\
\hline Cornbread & & & 3.2 & 5 \\
\hline Intake, mean \pm standard deviation & Men & Women & Men & Women \\
\hline Carbohydrate (g) & $288 \pm 143$ & $219 \pm 106$ & $273 \pm 151$ & $205 \pm 116$ \\
\hline Protein $(\mathrm{g})$ & $94 \pm 50$ & $66 \pm 33$ & $89 \pm 50$ & $63 \pm 38$ \\
\hline Fat $(\mathrm{g})$ & $96 \pm 54$ & $71 \pm 44$ & $94 \pm 61$ & $67 \pm 47$ \\
\hline Fibre (g) & $15.3 \pm 10.5$ & $12.7 \pm 8.2$ & $13.5 \pm 9.8$ & $10.7 \pm 8.5$ \\
\hline
\end{tabular}

here. Based on the pattern of these distributions for most foods, and for ease of later computation, portion sizes were designed with the second portion choices representing a standard reference amount (usually the median and most common size). The first choices were half of the reference portion, the third 1.5 times the reference portion, and the fourth twice the reference portion in order to capture the extra large servings that subsets of the population reported consuming.

\section{FFQ format}

Results of the field trials revealed that the grid format for combined frequency and portion sizes was confusing for the respondents. Participants responded favourably to the grid format for frequencies, but preferred portion sizes to be asked as separate questions following each frequency grid. For example, portion size choices were presented for cooked vegetables, rather than repeatedly for broccoli, carrots, corn and so on. In many cases, this also allowed for the collapsing of portion sizes of similar foods, previously found to be repetitive. Despite evidence of very large portions in the recall data, participants seemed reluctant to select the extra large category, suggesting that this label may hold negative connotations and could lead to underreporting if presented in this way. We therefore changed the portion sizes to standard reference amounts, rather than labelling them as small, medium, large and extra large. Additionally, we found that participants responded more rapidly when identifying the target sizes their portion was closest to, rather than ranges.

This new format (Appendix) also allowed for the inclusion of adjustment questions within each food group section throughout the questionnaire. Rather than including items such as milk in coffee on another line on the grid, or having a separate section for fat adjustment questions like removing skin on chicken, it was preferable to respondents to answer these questions at the end of each food group section. This, along with the inclusion of openended questions on specific cereal brands and additional foods not on the list, allowed for some simplification of foods listed in the grid.

The average time of completion for the FFQ was $45 \mathrm{~min}$ before modification. Modification did not lead to major changes in the list of food line items, with 142 in the final version. Rather, it led to changes in the ordering of items, changes in the names of some items and in the addition of 
Table 3 Top food contributors to B vitamin intakes in adults of the Lower Mississippi Delta, by race

\begin{tabular}{|c|c|c|c|c|}
\hline \multirow[b]{2}{*}{ Food } & \multicolumn{2}{|c|}{ White $(n=842)$} & \multicolumn{2}{|c|}{ African American $(n=857)$} \\
\hline & $\%$ & Rank & $\%$ & Rank \\
\hline \multicolumn{5}{|l|}{ Folate } \\
\hline White bread, rolls & 11.9 & 1 & 13.2 & 1 \\
\hline Regular breakfast cereals & 5.4 & 2 & 5.7 & 2 \\
\hline Tea & 4.9 & 3 & 4.6 & 4 \\
\hline Orange juice & 3.9 & 4 & 5.6 & 3 \\
\hline High-fibre cereals & 3.7 & 5 & & \\
\hline Rice & & & 3.5 & 5 \\
\hline \multicolumn{5}{|l|}{ Vitamin $\mathrm{B}_{6}$} \\
\hline Regular breakfast cereals & 5.5 & 1 & 5.7 & 2 \\
\hline Bananas & 5.2 & 2 & 5.4 & 3 \\
\hline Beefsteaks, roast, ribs & 4.6 & 3 & & \\
\hline Other potatoes & 4.4 & 4 & & \\
\hline Fried chicken & 4.2 & 5 & 9.1 & 1 \\
\hline Burgers, meatloaf & & & 4.6 & 4 \\
\hline Salty snacks (chips) & & & 4.5 & 5 \\
\hline \multicolumn{5}{|l|}{ Vitamin $B_{12}$} \\
\hline Burgers, meatloaf & 11.5 & 1 & 14.3 & 1 \\
\hline Beefsteaks, roast, ribs & 10.3 & 2 & & \\
\hline Fried fish & 5.8 & 3 & 8.9 & 2 \\
\hline $2 \%$ Milk & 5.7 & 4 & & \\
\hline Whole milk & 4.0 & 5 & & \\
\hline Fried liver & & & 7.2 & 3 \\
\hline Chicken liver & & & 6.9 & 4 \\
\hline Sausage & & & 5.7 & 5 \\
\hline Intake, mean \pm standard deviation & Men & Women & Men & Women \\
\hline Folate $(\mu \mathrm{g})$ & $398 \pm 236$ & $297 \pm 177$ & $338 \pm 209$ & $262 \pm 177$ \\
\hline Vitamin $B_{6}(m g)$ & $2.0 \pm 1.3$ & $1.4 \pm 0.9$ & $1.8 \pm 1.3$ & $1.3 \pm 0.8$ \\
\hline Vitamin $B_{12}(\mu \mathrm{g})$ & $5.8 \pm 5.3$ & $3.9 \pm 4.1$ & $4.5 \pm 5.1$ & $3.8 \pm 7.7$ \\
\hline
\end{tabular}

Table 4 Top food contributors to intakes of vitamins C, A and E from the Lower Mississippi Delta Nutrition Intervention Research Initiative Foods of our Delta Survey 2000

\begin{tabular}{|c|c|c|c|c|}
\hline \multirow[b]{2}{*}{ Food } & \multicolumn{2}{|c|}{ White $(n=842)$} & \multicolumn{2}{|c|}{ African American $(n=857)$} \\
\hline & $\%$ & Rank & $\%$ & Rank \\
\hline \multicolumn{5}{|l|}{ Vitamin C } \\
\hline Orange juice & 23.8 & 1 & 27.7 & 1 \\
\hline Fruit drinks & 6.6 & 2 & 21.2 & 2 \\
\hline Oranges & 6.0 & 3 & 5.5 & 3 \\
\hline Tomatoes & 4.6 & 4 & 3.2 & 4 \\
\hline Other potatoes & 3.7 & 5 & & \\
\hline Grapefruit juice & & & 3.2 & 5 \\
\hline \multicolumn{5}{|l|}{ Vitamin A } \\
\hline Carrots & 10.2 & 1 & & \\
\hline Sweet potatoes & 5.4 & 2 & 9.8 & 1 \\
\hline $2 \%$ Milk & 5.3 & 3 & & \\
\hline Regular breakfast cereals & 4.1 & 4 & 5.0 & 5 \\
\hline High-fibre cereals & 3.6 & 5 & & \\
\hline Chicken liver & & & 6.4 & 2 \\
\hline Greens & & & 6.3 & 3 \\
\hline Fried liver & & & 5.5 & 4 \\
\hline \multicolumn{5}{|l|}{ Vitamin $\mathrm{E}$} \\
\hline Mayonnaise, salad dressing & 9.1 & 1 & 5.8 & 3 \\
\hline Salty snacks (chips) & 4.5 & 2 & 12.2 & 1 \\
\hline White bread, rolls & 4.3 & 3 & 4.5 & 4 \\
\hline Fried fish & 4.3 & 4 & 6.7 & 2 \\
\hline Highly fortified cereals & 4.3 & 5 & & \\
\hline Fried chicken & & & 3.9 & 5 \\
\hline Intake, mean \pm standard deviation & Men & Women & Men & Women \\
\hline Vitamin C (mg) & $80 \pm 91$ & $73 \pm 85$ & $102 \pm 112$ & $86 \pm 90$ \\
\hline Vitamin A (RE) & $873 \pm 999$ & $760 \pm 833$ & $756 \pm 1250$ & $692 \pm 1247$ \\
\hline Vitamin E (TE) & $10.3 \pm 11.6$ & $8.2 \pm 7.0$ & $10.1 \pm 25.5$ & $6.6 \pm 5.3$ \\
\hline
\end{tabular}

RE - retinol equivalents; TE - tocopherol equivalents. 
Table 5 Top food contributors to mineral intakes from the Lower Mississippi Delta Nutrition Intervention Research Initiative Foods of our Delta Survey 2000

\begin{tabular}{|c|c|c|c|c|}
\hline \multirow[b]{2}{*}{ Food } & \multicolumn{2}{|c|}{ White $(n=842)$} & \multicolumn{2}{|c|}{ African American $(n=857)$} \\
\hline & $\%$ & Rank & $\%$ & Rank \\
\hline \multicolumn{5}{|l|}{ Calcium } \\
\hline $2 \%$ Milk & 12.3 & 1 & 6.5 & 4 \\
\hline Cheese & 9.1 & 2 & 10.2 & 1 \\
\hline Whole milk & 8.7 & 3 & 7.9 & 2 \\
\hline White bread, rolls & 6.0 & 4 & 7.8 & 3 \\
\hline Skimmed or $1 \%$ milk & 5.2 & 5 & & \\
\hline Cornbread & & & 4.6 & 5 \\
\hline \multicolumn{5}{|l|}{ Iron } \\
\hline White bread, rolls & 8.5 & 1 & 9.9 & 1 \\
\hline Regular breakfast cereals & 7.5 & 2 & 5.9 & 3 \\
\hline High-fibre cereals & 5.5 & 3 & & \\
\hline Burgers, meatloaf & 4.6 & 4 & 6.1 & 2 \\
\hline Beefsteaks, roast & 3.6 & 5 & & \\
\hline Fried chicken & & & 3.7 & 4 \\
\hline Grits & & & 3.0 & 5 \\
\hline \multicolumn{5}{|l|}{ Zinc } \\
\hline Beefsteaks, roast & 9.5 & 1 & 4.6 & 3 \\
\hline Burgers, meatloaf & 9.4 & 2 & 12.5 & 1 \\
\hline Gumbo & 4.0 & 3 & & \\
\hline High-fibre cereals & 3.2 & 4 & & \\
\hline Luncheon meats & 2.7 & 5 & & \\
\hline Fried chicken & & & 6.4 & 2 \\
\hline Poultry, not fried & & & 4.4 & 4 \\
\hline Sausage & & & 3.9 & 5 \\
\hline \multicolumn{5}{|l|}{ Magnesium } \\
\hline Coffee & 6.7 & 1 & & \\
\hline $2 \%$ Milk & 3.8 & 2 & & \\
\hline White bread, rolls & 3.7 & 3 & 5.0 & 2 \\
\hline Salty snacks (chips) & 3.2 & 4 & 5.4 & 1 \\
\hline High-fibre cereals & 2.9 & 5 & & \\
\hline Orange juice & & & 3.9 & 3 \\
\hline Fried chicken & & & 3.8 & 4 \\
\hline Burgers, meatloaf & & & 3.4 & 5 \\
\hline Intake, mean \pm standard deviation & Men & Women & Men & Women \\
\hline Calcium (mg) & $841 \pm 633$ & $662 \pm 420$ & $643 \pm 443$ & $506 \pm 407$ \\
\hline Iron (mg) & $16.9 \pm 11.9$ & $12.8 \pm 7.9$ & $14.7 \pm 8.5$ & $10.9 \pm 6.9$ \\
\hline Zinc (mg) & $14.2 \pm 12.0$ & $10.0 \pm 7.9$ & $11.7 \pm 9.2$ & $8.3 \pm 6.1$ \\
\hline Magnesium (mg) & $319 \pm 192$ & $234 \pm 115$ & $248 \pm 147$ & $182 \pm 112$ \\
\hline
\end{tabular}

recipe questions to clarify the preparation methods. Although separation of the portion sizes from the grid format and the addition of preparation questions led to increased physical length, it did not increase the time of completion, which remained at approximately $45 \mathrm{~min}$ with no apparent differences in time of completion by race or sex.

\section{Discussion}

The accurate assessment of dietary intake is critical to the success of population-based studies that link dietary behaviour with health outcomes. Although a single 24hour dietary recall per person has been shown to represent mean intake for a large group, it is well known that this method is less successful in ranking individual food and nutrient intakes ${ }^{14}$. Use of a single 24-hour dietary intake recall results in misclassification of individual usual intake due to normal day-to-day variation in intake, and makes it more difficult to see existing associations between food or nutrient intake and disease outcomes for individuals ${ }^{2}$. For some nutrients, many days of dietary intake are needed to average this variation to be representative of individual nutrient intake ${ }^{15}$. Both the collection and processing of dietary recall or food intake record data are also demanding and expensive. For these reasons, the FFQ is used extensively in population studies $^{2}$.

The most commonly used FFQs were designed for use in the general US population. The foods listed capture either the greatest proportion of total nutrient intake in the population $^{3}$ or the greatest variance in intake ${ }^{4}$ and contain assumptions about average portion size. In either case, subgroups of the population with diets that vary from the norm are unlikely to be represented in these decisions. The importance of a culturally and regionally specific questionnaire was demonstrated previously among the Puerto Rican population in the north-eastern USA, where it was shown that use of a nationally used questionnaire would not only underestimate intakes of energy and 
Table 6 Regional foods added to the Lower Mississippi Delta Nutrition Intervention Research Initiative Food Frequency Questionnaire for Adults*

\begin{tabular}{ll}
\hline Food & Note \\
\hline Biscuits & Made with white flour, frequently served with gravy \\
Broccoli and rice casserole & Popular casserole that also contains processed cheese \\
Cheese dip & Commercially processed \\
Chicken and dumplings, pot pie & Chicken in gravy with flour dumplings or pie crust \\
Cracklings & Deep fried pork skin \\
Fried beef (chicken fried steak) & Beef loin, flattened, battered and fried \\
Fried catfish, fish sandwich & Usually deep fried \\
Fried potatoes: potato logs & Large pieces of potato, deep fried \\
Fruit drinks: orangeade, lemonade & Usually commercially prepared, condensed or powdered \\
Game: venison, squirrel & From local hunters \\
Gravy (on meat or biscuits) & Usually prepared from a commercial mix \\
Greens: mustard, turnip, collards, poke salat & Locally popular green vegetables \\
Grits & Corn-based cereal, cooked like rice \\
Home-made soup: gumbo & Usually contains okra, rice, sausage and special seasonings \\
Jambalaya, dirty rice & Rice recipe with meat or fish and special seasonings \\
Neck bones, ham hock, pig's feet & May be smoked or pickled \\
Okra & Locally popular vegetable \\
Organ meats: chitterlings & Fried intestines \\
Peas: field, black-eyed, purple hull & Locally popular peas \\
Powdered drink mixes & Mostly sugar with artificial flavour \\
Root crops: turnips, rutabaga & Locally popular root vegetables \\
Shellfish: crawfish & River crustacean \\
Sweet potato pie & Sweet pie made with sweet potatoes, milk and sugar \\
Sweet tea & Iced tea prepared with sugar \\
\hline
\end{tabular}

* Foods identified on the 24-hour dietary recalls that contributed at least $0.5 \%$ of energy or of any other nutrient examined.

nutrients for this group but could also lead to biased comparisons with non-Hispanic whites ${ }^{16}$. In addition to consumption of foods not on the food list, portion sizes of ethnic subgroups can vary widely from that assumed for the general population. Furthermore, unique preparations of commonly used foods by a subgroup may have a major impact on the nutrient content of the diet.

This analysis indicates that the population of the LMD region of the USA does consume many foods not on existing FFQs. Furthermore, within the Delta region, differences in dietary patterns were evident between white and African American residents. For example, white Delta adults consumed considerably more 'sweet tea' (sugar added to hot tea and then iced), while the African American adults were much more likely to consume fruit drinks. The importance of these beverages in this population required reconsideration of their placement on the questionnaire and of the detail required for measuring them correctly. Additionally, cornbread, grits, greens, sausage and liver appeared as important contributors of specific nutrients for the African American, and gumbo for the white adults in the LMD. Consideration of these groups separately ensures that the most important foods for each group are represented in a single FFQ that can accurately capture the diet of both. We found that a questionnaire for the LMD required numerous differences from those nationally used, including several new foods, food names as used in the local context, specific food preparation details, increased portion sizes and locally defined recipes.

One limitation of the data used to develop the food list was the collection of recall information only between January and June. It is therefore possible that some seasonal foods were underrepresented in the food intake rankings. However, we tested the FFQs during the summer months, and specifically requested whether there were any additional foods that were consumed frequently. While this request led to changes in recipes, it did not lead to the need to add additional foods to the questionnaire.

The concerns with questionnaire completion that we noted in our field tests were similar to those identified by others using cognitive interviewing techniques. For example, based on questionnaire testing, the NCI abandoned the grid format ${ }^{17}$. The Delta NIRI experience differed, however, as we found that the grid was well accepted for frequency but not for portion size. Our final form, therefore, includes alternating sections of frequency grids, expanded sections for portion size and adjustment questions, allowing for a more natural flow of related information, while obtaining more precise detail on individual food preparations. The inclusion of four rather than three portion size options allowed individuals in the upper tail of the distribution to report their portion sizes more accurately, thereby reducing underestimation of intake of specific foods consumed in large quantity by some individuals. The use of specific numbers for each portion size allowed the respondent to think of their own portion in relation to the closest portion. This was found to be easier and faster than either attempting to calculate from information only for a medium serving or from considering the information included in ranges.

In addition to providing valuable data from which to design the FFQ, the ranking of food items to nutrient intake provides an important look at the diets consumed by population subgroups. The patterns described here 
Table 7 Portion size distributions for selected foods (g), as consumed by adults of the Lower Mississippi Delta

\begin{tabular}{|c|c|c|c|}
\hline Food item & 15th percentile & Median & 85th percentile \\
\hline Apple & 69 & 138 & 212 \\
\hline Bacon & 8 & 16 & 32 \\
\hline Beef & 51 & 124 & 276 \\
\hline Beer & 360 & 720 & 1440 \\
\hline Biscuit & 29 & 51 & 90 \\
\hline Butter & 5 & 8 & 16 \\
\hline Cake & 18 & 40 & 87 \\
\hline Candy & 4 & 13 & 40 \\
\hline Carrot & 8 & 32 & 78 \\
\hline Cheese & 14 & 26 & 49 \\
\hline Coffee & 179 & 253 & 592 \\
\hline Corn & 41 & 85 & 164 \\
\hline Cornbread & 21 & 63 & 112 \\
\hline Eggs & 40 & 80 & 118 \\
\hline Fruit drink & 188 & 358 & 579 \\
\hline Fried chicken & 45 & 86 & 153 \\
\hline Fried fish & 75 & 150 & 298 \\
\hline French fries & 35 & 70 & 125 \\
\hline Gravy & 14 & 31 & 120 \\
\hline Greens & 36 & 88 & 164 \\
\hline Grits & 98 & 139 & 242 \\
\hline Ham & 21 & 42 & 85 \\
\hline Hamburger & 68 & 113 & 227 \\
\hline Hot dog & 27 & 57 & 118 \\
\hline Ice cream & 59 & 116 & 241 \\
\hline Liquor & 42 & 111 & 348 \\
\hline Orange & 83 & 131 & 184 \\
\hline Peas & 33 & 88 & 170 \\
\hline Pie & 69 & 114 & 198 \\
\hline Pizza & 63 & 163 & 284 \\
\hline Pork & 44 & 85 & 186 \\
\hline Potato chips & 14 & 28 & 74 \\
\hline Rice & 44 & 119 & 171 \\
\hline Salad dressing & 5 & 15 & 39 \\
\hline Soda & 248 & 369 & 553 \\
\hline Soup & 112 & 241 & 494 \\
\hline Spaghetti & 36 & 107 & 210 \\
\hline Sweet potato & 45 & 98 & 150 \\
\hline Sweet tea & 237 & 474 & 858 \\
\hline Tomato & 15 & 59 & 184 \\
\hline Tuna & 9 & 80 & 170 \\
\hline Whole milk & 61 & 203 & 366 \\
\hline White bread & 23 & 40 & 60 \\
\hline
\end{tabular}

show that both racial groups in the LMD tended to have higher intakes of soft drinks, other sweetened drinks, fried chicken, fried fish and pork than the general US population ${ }^{10}$. Together, soft drinks, white bread, ground beef and salty snacks contribute more than $20 \%$ of energy in the LMD population, while few fruits or vegetables appear. The ranking of food sources reveals that when intake is low, as in the example of magnesium among African Americans, the primary source may appear unusual, such as salty snacks. The prominence of white bread and salty snacks in the lists of contributors to several nutrients illustrates that good sources of these nutrients are not included as part of the dietary pattern.

The LMD is one of the poorest regions of the country and the states therein have high prevalences of obesity, hypertension, diabetes, heart disease, cancer and other diet-related conditions ${ }^{5,18-20}$. An earlier report documented lower intakes of protein and most vitamins and minerals in this sample relative to a national survey ${ }^{6}$. The results presented here clarify the food choices in these populations and suggest areas for further research and nutrition intervention.

The experience described here illustrates the complexity involved in the development or modification of an FFQ for populations with diets that differ from those already in use. In each case, not only the food items but also the preparation methods, portion sizes and internal variation within the population must be fully considered. Other important considerations include the educational level of the population, their previous exposure (or lack thereof) to research questionnaires, and the clarity and interpretability of the tool, within these contexts.

The development of this regionally specific FFQ for adults will allow future research on diet and health outcomes and will be of value to scientists studying food and nutrient intakes of African Americans and white adults in the Southern United States. Calibration of this instrument, in both a full and abbreviated form, is in progress with a subset of participants in the Jackson Heart Study, where each version will be compared with multiple 24-hour recalls and serum nutrient biomarkers. Once fully calibrated, the use of this FFQ will also facilitate studies of dietary change through interventions, thereby contributing to the increasing evidence that dietary improvements can have a powerful effect on nutritional status and health.

\section{Acknowledgements}

This work was supported in part by USDA, Agricultural Research Service Co-operative Agreements 58-6251-20008 and 58-1950-9-001.

\section{References}

1 Kipnis V, Subar AF, Midthune D, Freedman LS, BallardBarbash R, Troiano RP, et al. Structure of dietary measurement error: results of the OPEN biomarker study. American Journal of Epidemiology 2003; 158: 14-21, discussion 22-6.

2 Willett W. Nutritional Epidemiology, 2nd ed. New York: Oxford University Press, 1998.

3 Block G, Hartman AM, Dresser CM, Carroll MD, Gannon J, Gardner L. A data-based approach to diet questionnaire design and testing. American Journal of Epidemiology 1986; 124: 453-69.

4 Willett WC, Sampson L, Stampfer MJ, Rosner B, Bain C, Witschi J, et al. Reproducibility and validity of a semiquantitative food frequency questionnaire. American Journal of Epidemiology 1985; 122: 51-65.

5 Pickle L, Mungiole M, Jones G, White A. Atlas of United States Mortality. Hyattsville, MD: National Center for Health Statistics, 1997.

6 Champagne CM, Bogle ML, McGee BB, Yadrick K, Allen HR, Kramer TR, et al. Dietary intake in the lower Mississippi delta region: results from the Foods of our Delta Study. Journal of the American Dietetic Association 2004; 104: 199-207.

7 Bogle M, Stuff J, Davis L, Forrester I, Strickland E, Casey PH, et al. Validity of a telephone-administered 24-hour dietary recall in telephone and non-telephone households in the 
rural Lower Mississippi Delta region. Journal of the American Dietetic Association 2001; 101: 216-22.

8 Guenther P, DeMaio T, Ingwersen L, Berlin M. The multiplepass approach for the 24-h recall in the Continuing Survey of Food Intakes by Individuals, 1994-1996. American Journal of Clinical Nutrition 1997; 65(Suppl.): $1316 \mathrm{~S}$.

9 US Department of Agriculture/Agricultural Research Service. Food Surveys Research Group Recipe Processing System (RPS) Version 2.04 - 1998 CSFII Data. Beltsville, MD: Agricultural Research Service, 2000.

10 Subar AF, Krebs-Smith SM, Cook A, Kahle LL. Dietary sources of nutrients among US adults, 1989 to 1991. Journal of the American Dietetic Association 1998; 98: 537-47.

11 SAS Institute, Inc. The SAS System for Windows. Release 8. Cary, NC: SAS Institute, Inc., 1999.

12 Kristal AR, Shattuck AL, Henry HJ, Fowler AS. Rapid assessment of dietary intake of fat, fiber, and saturated fat validity of an instrument suitable for community intervention research and nutritional surveillance. American Journal of Health Promotion 1990; 4: 288-95.

13 Institute of Medicine. Dietary Reference Intakes for Calcium, Phosphorus, Magnesium, Vitamin D and Fluoride. Washington, DC: National Academy Press, 1997.

14 Beaton GH, Milner J, Corey P, McGurie V, Cousins M, Stewart $\mathrm{E}$, et al. Sources of variance in 24-hour dietary recall data: implications for nutrition study design and interpretation American Journal of Clinical Nutrition 1979; 32: 2546-59.
15 Beaton GH, Milner J, McGuire V, Feather TE, Little JA. Source of variance in 24-hour dietary recall data: implications for nutrition study design and interpretation. Carbohydrate sources, vitamins, and minerals. American Journal of Clinical Nutrition 1983; 37: 986-95.

16 Tucker KL, Bianchi LA, Maras J, Bermudez OI. Adaptation of a food frequency questionnaire to assess diets of Puerto Rican and non-Hispanic adults. American Journal of Epidemiology 1998; 148: 507-18.

17 Subar AF, Thompson PE, Smith AF, Jobe JB, Ziegler RG, Potischman $\mathrm{N}$, et al. Improving food frequency questionnaires: a quantitative approach using cognitive interviewing. Journal of the American Dietetic Association 1995; 95: $781-8$.

18 Harsha D, Thornton A. Health status of adults. In: Harrison G, ed. Nutrition and Health Status in the Lower Mississippi Delta of Arkansas, Louisiana, and Mississippi: A Review of Existing Data. Lower Mississippi Delta Nutrition Intervention Research Consortium. Rockville, MD: Westat, 1997; 89-108.

19 Mokdad AH, Serdula MK, Dietz WH, Bowman BA, Marks JS Koplan JP. The spread of the obesity epidemic in the United States, 1991-1998. Journal of the American Medical Association 1999; 282: 1519-22.

20 Wolz M, Cutler J, Roccella EJ, Rohde F, Thom T, Burt V. Statement from the National High Blood Pressure Education Program: prevalence of hypertension. American Journal of Hypertension 2000; 13: 103-4.

\section{Appendix - Cereal section from the revised food-frequency questionnaire}

\begin{tabular}{|c|c|c|c|c|c|c|c|c|c|c|}
\hline \multicolumn{11}{|l|}{ CEREALS } \\
\hline & Never & $\begin{array}{l}\text { Less than } \\
1 \times \text { per month }\end{array}$ & $\begin{array}{l}1 \times \text { per } \\
\text { month }\end{array}$ & $\begin{array}{c}2-3 \times \text { per } \\
\text { month }\end{array}$ & $\begin{array}{c}1 \times \text { per } \\
\text { week }\end{array}$ & $\begin{array}{l}2 \times \text { per } \\
\text { week }\end{array}$ & $\begin{array}{c}3-4 \times \text { per } \\
\text { week }\end{array}$ & $\begin{array}{c}5-6 \times \text { per } \\
\text { week }\end{array}$ & $\begin{array}{l}1 \times \text { per } \\
\text { day }\end{array}$ & $\begin{array}{l}2 \times \text { or more } \\
\text { per day }\end{array}$ \\
\hline Cold cereals & O & ○ & ○ & ○ & ○ & ○ & $\bigcirc$ & $\bigcirc$ & O & $\bigcirc$ \\
\hline Grits & O & O & ○ & ○ & ○ & O & ○ & ○ & O & O \\
\hline Oatmeal & $\bigcirc$ & $\bigcirc$ & $\bigcirc$ & $\bigcirc$ & $\bigcirc$ & $\bigcirc$ & $\bigcirc$ & $\bigcirc$ & ○ & ○ \\
\hline $\begin{array}{l}\text { Other cooked cereals } \\
\text { (e.g. Cream of Wheat or Rice) }\end{array}$ & ○ & $\bigcirc$ & O & O & $\bigcirc$ & O & ○ & O & O & O \\
\hline
\end{tabular}

When you eat cold cereal, your portion is usually closest to...
O $1 / 2$ cup
O 1 cup
O $11 / 2$ cups
O 2 cups or more

When you eat hot cereal (e.g. grits, oatmeal or other cooked cereals), your portion is usually closest to...
O 1/4 cup
$\bigcirc 1 / 2$ cup
3/4 cup
O cup or more

If you add milk, it is usually closest to...
O don't use
O $1 / 2$ cup
$\bigcirc 1$ cup
O $11 / 2$ cups
O 2 cups or more

When you eat cereal (hot or cold), it is usually taken...
$\bigcirc$ without sugar
○ 1-2 teaspoons
O 3 teaspoons of sugar
O 4 or more teaspoons of sugar
$O$ with artificial sweetener

If you use cold breakfast cereal, what two types (include brand name) do you use most often? (e.g. Kellogg's Corn Flakes) $O$ Do not know brand name

1.

2.

\begin{tabular}{llllllllll}
\hline 0 & 1 & 2 & 3 & 4 & 5 & 6 & 7 & 8 & 9 \\
\hline 0 & 1 & 2 & 3 & 4 & 5 & 6 & 7 & 8 & 9
\end{tabular}

